Acta Crystallographica Section E

Structure Reports

Online

ISSN 1600-5368

\title{
A neo-clerodane diterpene from Teucrium tomentosum. Corrigendum
}

\section{S. Soundarya Devi, ${ }^{a}$ R. Malathi, ${ }^{\text {a }}$ S. S. Rajan, ${ }^{\text {a* }}$ S. Aravind, ${ }^{\text {b }}$} G. N. Krishnakumarib and K. Ravikumar ${ }^{\mathrm{C}}$

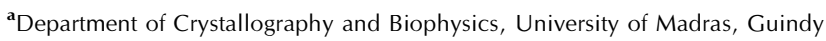
Campus, Chennai 600 025, India, 'b SPIC Science Foundation, Guindy, Chennai 600 032, India, and 'Indian Institute of Chemical Technology, Hyderabad 500 007, India

Correspondence e-mail: ssrajansai@yahoo.com

Received 28 April 2009; accepted 29 April 2009

The chemical name of the title compound in the paper by Devi, Malathi, Rajan, Aravind, Krishnakumari \& Ravikumar [Acta Cryst. (2004), E60, o117-o119] is corrected and the structural diagram is updated.

In the paper by Devi, Malathi, Rajan, Aravind, Krishnakumari \& Ravikumar [Acta Cryst. (2004), E60, o117-o119], the chemical name given in the Abstract should be '15,16-epoxy$6 \beta$-hydroxyneo-cleroda-3,13(16),14-triene-18,19:20,12-diolide'. An updated structural diagram is shown below.<smiles>C[C@H]1C[C@@H](O)[C@]2(CCOC2=O)C2CCC=C3C(=O)OC[C@@]321</smiles> 